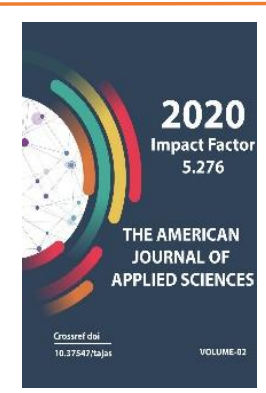

\title{
Classification Of Gastronomy Units
}

\author{
Nurkhon Nuraliyevna Rasulova \\ 2-Course Master's Degree, National University Of Uzbekistan, Tashkent, Uzbekistan
}

Copyright: Original

content from this work

may be used under the

terms of the creative

commons attributes

4.0 licence.

\section{ABSTRACT}

In this article, the units of gastronomy are classified. In the process of classification, attention is paid to the information about the dishes and foods of the Turkic peoples in M. Kashgari's "Devonu lug'otit turk". Gastronomy is an important part of the lexical richness of the peoples of the East, including the Uzbek people. It reflects the national qualities of the Uzbeks. Applying to gastronomic units is not only interesting but also very relevant in the study of the Uzbek language.

\section{KEYWORDS}

Gastronomy, M.Kashgari, Devonu lug'otit turk, food, delicacies, bakery products, dairy products, meat products, confectionery, beverages, spices, objective and subjective factors.

\section{INTRODUCTION}

The Uzbek language, one of the oldest and richest languages in the world, is an invaluable asset of our people, a spiritual heritage inherited from our ancestors. Uzbek is a very rich language. Much attention is paid to its further enrichment, the introduction of Uzbek terms, the collection of dialect words, the re- use of obsolete words. In his speech at the ceremony dedicated to the 30th anniversary of the official status of the Uzbek language, President Shavkat Mirziyoyev said: "Uzbek, one of the oldest and richest languages in the world, is a symbol of our national identity and independent statehood, invaluable spiritual 
wealth and great value for our people." Besides, the fact that the decree signed by the President "On measures to radically increase the prestige and status of the Uzbek language as the state language" addresses issues such as raising and enriching the Uzbek language, teaching the Uzbek language abroad shows special attention to the language in our country.

\section{ANALYSIS AND RESULTS}

Words related to gastronomy are an important part of the lexical richness of the Uzbek language. It reflects the national qualities of the Uzbeks. Let's take a brief look at the term "gastronomy". Gastronomy is the study of the relationship between culture and food, and it also refers to the general name of high-quality food products and the foods that are made from them. As long as a person lives in a society, he is engaged in some activity in that society. He contributes materially and spiritually to society through his work. A person needs energy in the performance of such work. Naturally, people get this energy from food. In this sense, Abu Ali ibn Sina's statement, "Some live only to eat, and I eat to live," is true, and states that the purpose of human existence is to work. [2] Gastronomy is the study of the relationship between the culture and food of a particular country, the process of cooking, and the history of its origin.

Oriental peoples, including the Uzbek people, have their national dishes and their history of preparation. M. Kashgari's work "Devonu lug'otit turk" reflects the process of preparation of food and dishes, types of food, and very important information about household items used in cooking and consumption. According to M. Kashgari, the traditional food of the settled Turkic peoples consisted mainly of agricultural products, cereals, vegetables and fruits, while the nomadic Turkic peoples used more dairy and meat products in their diets [3]. If we pay attention to the information in M. Kashgari's
"Devonu lug'otit turk", we will see that the author classifies a food as follows:

1. Bread products. According to $M$. Kashgari, the Turkic tribes had such types of bread as "Bushkal", "Isbiri", "Komuch", "Kijma", "Chukmi" [4]. These breads differed in taste, method of preparation, and ingredients.

2. Pastries. Pastries also played an important role in the daily life of our ancestors. The work also contains information about "Umoch", "Ugra”, "Tutmach", and "Manti" and "Lagmon", which are still popular today.

3. Dairy-related products. In the course of reading the book, we learn that the Turkic peoples called sour cream "Ikduk", cream "Qajaq", cheese "Uzitma", and liquid sour cream with fruit, now called yogurt, "Suyuq jogurt".

4. Rice and cereal dishes. M. Kashgari gives the following names of dishes of Turkic peoples, which are prepared with the addition of rice and cereals: "Uva", "Bukhsi", "Suruch", "Korshak", "Kavut".

5. Meat dishes. Because most Turkic peoples are engaged in feeding animals, meat is used in many dishes. "Sugut", "Tobik", "Kazi jag", "Simsimrak" are the names of meat dishes mentioned in the work.

6. Liquid foods. Soups such as "Bulduni", "Oz", "Mon", "Lantu", "Samduj" were prepared by our ancestors.

7. Drinks. M. Kashgari's "Devonu lug'otit turk" contains valuable information about the origin, taste and flavor of beverages such as boza, juice and koumiss.

\section{PART OF THE EXPERIMENTS}

Food names today are referred to by the term gastronomy. Gastronomy should not be understood as just food. Gastronomy is the 
general name for the food that enters the stomach, the sum of the energy products that human beings need to survive. We decided to divide the gastronomic units into the following groups:

1. Delicacies. Food is an integral part of the culture of man and the society in which he lives. The distinctive features of the national cuisine are the ancient roots of the culture of a nation. When a person eats food, he is exposed to a certain culture. The Uzbek national cuisine has a centuries-old history and is world-renowned for its unique cooking style, the uniqueness of the spices used in the dishes, and the culture of serving cooked food. The peculiarity of Uzbek cuisine is that the taste of delicacies depends on two factors. The first factor is the sort, variety, chemical composition of the ingredients, whether they are ripe or raw, fresh or well-preserved, and, in general, diversity, which is objective. The second factor is subjective and depends on the experience, skills and knowledge of the cook - the appearance, aroma, excellent taste of the food, the creation of recipes, processing, cooking according to certain rules, readability, cleanliness, efficiency, and especially skill. [5]. There are many types of food, such as iced dishes, non-fluid dishes, fluid dishes, and they are the beauty of the table.

2. Bread and bakery products. Bread reflects the human qualities of the Uzbek people, such as hospitality, diligence, courtesy, simplicity. Our people have different customs and traditions related to bread, which say that bread is a great blessing and should not be wasted. Bread and bakery products are the leaders among gastronomic units. The reason is that there are several types of bread. Uzbek tandoor bread is made in three ways: home bread, wedding bread, and market bread, and there are hundreds of varieties. The most popular Uzbek breads are Obi bread, patir, milk bread, patrak bread, lochira, layered bread, layered patir, shirmoy bread, kazan bread.

3. Cereals and grain products. In Uzbek cuisine, both in ancient times and today, it is possible to prepare very tasty dishes from mosh, beans, peas and rice. Such cereals are valuable for their nutritional value and energy. These products are not only used in Uzbek cuisine, of course. In each national cuisine, these products come in different flavors and looks. Wheat is used not only for bread and pastries, but also for grinding wheat and making various cereals. Wheat flour is also used to make semi-finished products such as noodles, pasta, and a variety of pastries.

4. $\quad$ Fat and fat products. Fats are one of the main components of food and are a source of substances and energy necessary for the human body. Fats accumulate mainly in the seeds of plants, and the fruit or bark of some plants. In animals and fish, fats accumulate mainly in their subcutaneous adipose tissue or in the adipose tissue that surrounds the organs that are most actively involved in the body's activities [6]. Vegetable oils such as cotton, sunflower, flax, sesame, and olive give a special flavor to dishes and make salads more nutritious. Animal fats are used to soften the dough, to give the food a pleasant aroma and taste.

5. Fruits and vegetables. Fruits and vegetables play an important role in cooking. Fruits and vegetables are a major part of our daily diet. They can be cooked or eaten raw. Fruits and vegetables are used not only in 
cooking but also in decorating them. Fruits and vegetables give the food a special flavor and appearance. They are rich in nutrients, and also increase the volume of food and help digest food. Cucumbers, onions, garlic, radishes, turnips are also used for healing. Also, daugh food, kazi, and meat dishes are harder to digest. Therefore, it is easier to digest such foods with fruits and vegetables. Palov is the most popular of the national dishes. That's why the palov is eaten with a salad of tomatoes and cucumbers. Of course, vegetables such as onions, tomatoes, cucumbers, and radishes are eaten with kebabs, fries, iced meat and kazi. It is useful to have fruit before or after eating manti, dumplings and fish, also, it is good to have a melon or watermelon before having a soup.

6. Meat and meat products. Meat has been a favorite and nutritious food of mankind since ancient times. It is also a meat product that makes dishes like somsa, chuchvara, kebab, manti, halim delicious, and favorable. Mutton is mainly used in Uzbek delicacies: mutton (mutton and lamb), beef (beef, bull, veal, and specially fattened beef), horse meat (specially bred horse and foal meat), chicken (hen, rooster, and specially fed broiler meat), partly meet of duck, goose, turkey, quail, sparrow, pheasant. Rarely used domestic animals are camel, goat, and rabbit meat, and hunted animals are argali and gazelle meat. Sausages are also one of the most popular meat products today. While the sausage is a bit more complicated to make, it is mostly made up of cooked, smoked, raw smoked batches. For the sausage, the soft and semi-soft meat of the animal is used. Meats of different hardness are minced. It is mixed with oil, flour, and various spices. Meat and meat products are also very important for gastronomy.

7. Milk and dairy products. If we look at the shelves, we can see that there are many types of milk and dairy products. In ancient times, milk was used only to make sour cream, cream, butter, and buttermilk. The list now includes cottage cheese, cheese, yogurt, sour cream, condensed milk, and cheese. In Uzbek cuisine, milk is served fresh or boiled for breakfast. Cow's milk is mainly used for breakfast while goat's and sheep's milk is used in the mountains. Horse milk is used to make kumiz and camel milk is used to make kimran. It is possible to consume milk and dairy products themselves, as well as to prepare various dishes, salads, and pastries with the help of these ingredients.

8. Confectionery. Confectionery, which is often used to decorate the table, is good for digestion if eaten after a meal. Our people make confectionery on good days and holidays to make our lives sweeter. Sugar, chocolate, and biscuits will be served to the guests, and delicious cakes will be baked for birthdays and weddings. Confectionery is a food product that retains a large amount of sugar, has a high energy value (caloric content), and is well digested, differs from other products by its taste, aroma, appearance. [7]. Confectionery products are divided into two groups: sugary and floury. Each of these groups includes several types of products. Sugary products include caramel, candy, marmalade, chocolate, iris, halva, sugary oriental sweets. Flour confectionery is made by adding a large amount of sugar, fat, eggs, and other products along with the flour. These include biscuits, 
galettes, cakes, rolls, cakes, and pastries.

9. Drinks. Liquids prepared for human consumption, mainly to quench thirst, are called drinks. The most common drink is freshwater. Water is an important fluid for humans and other living organisms. Drinks that can be drunk both hot and cold are tea and milk. Products such as sour cream and guja are considered both beverages and food. Also, fruit compotes and vegetable juices are among the drinks. While these naturally made drinks are very good for human health, alcohol and fizzy drinks are bad for your health. Consumption of fizzy beverages is harmful to humans. This is because medicine has shown that gas in the drink can cause calcium absorption, memory loss, bone loss, and liver damage. It is therefore recommended to drink natural beverages.

10. Spices. Spices are widely used in all cuisines of the world. It is known that spices and herbs are widely used in cooking in hot climates. This is because in hot climates, the appetite is often suppressed and there is a situation in which people do not want to eat [8]. At this time, various spices are used to whet the appetite. There are so many wild and cultivated plants in nature that their bodies, leaves, flowers, and fruits have a fragrant, bitter, sour, and sweet taste. These herbs are called spices. In the Uzbek national cuisine, spices and herbs such as cumin, sedan, basil, barley, kashnich, ginger, jag-jag, spinach, horseradish, semizot, kiyikot have a special place. In the Uzbek national cuisine, spices and herbs such as cumin, sedan, basil, barley, kashnich, ginger, jag-jag, spinach, horseradish, semizot, kiyikot have a special place.
The taste of them will be unforgettable for foreigners forever.

\section{CONCLUSION}

- Gastronomy is not just about food, it is about all the foods that give a person the energy they need to live.

- $\quad$ Oriental peoples, including the Uzbek people, have their national dishes and their history of preparation.

- Gastronomy is also interested in the process of cooking and the history of its origin in the study of the relationship between the culture and food of a particular country.

- The peculiarity of Uzbek cuisine is that the taste of delicacies depends on objective and subjective factors.

- The collection and analysis of gastronomic units are one of the most pressing issues of modern linguistics.

\section{REFERENCES}

1. From the solemn speech of Shavkat Mirziyoyev dedicated to the 30th anniversary of the status of the Uzbek language as the state language.

2. Abu Ali ibn Sino. Laws of Medicine. Book II. Tashkent-1956

3. Abdulakhatov $\mathrm{N}$. and others. The study of lexical units in Mahmud Kashgari's "Devonu lug'atit turk". Tashkent- 2013

4. Mahmud Kashgari "Devonu lug'atit turk", V-1, pp:126, 159, 444, 445

5. Mahmudov K. Uzbek delicacies. Tashkent-1989

6. Dustjanov B. Khorezm cuisine. Tashkent-1994

7. Vasiyev M.G. Basics of food technology. Tashkent-2012

8. Tilovov M.R. and others. Food hygiene. Tashkent- 2007 